\title{
Pattern of Presentation and Associated Morbidities of Women Presenting with Postmenopausal Bleeding
}

\author{
Johnbosco E. Mamah ${ }^{1}$, Kanario A. Onyebuchi' ${ }^{1}$, Robinson C. Onoh ${ }^{1}$, Love Okafor ${ }^{1}$, Zubaida Aliyu ${ }^{2}$ \\ ${ }^{1}$ Federal Teaching Hospital Abakaliki, Ebonyi State, Nigeria \\ ${ }^{2}$ Homerton University Hospital, London, UK \\ Email: *johnbosco.mamah.pg78545@unn.edu.ng
}

How to cite this paper: Mamah, J.E. Onyebuchi, K.A., Onoh, R.C., Okafor, L. and Aliyu, Z. (2020) Pattern of Presentation and Associated Morbidities of Women Presenting with Postmenopausal Bleeding. Open Journal of Obstetrics and Gynecology, 10, 1631-1636.

https://doi.org/10.4236/ojog.2020.10110146

Received: October 24, 2020

Accepted: November 24, 2020

Published: November 27, 2020

Copyright $\odot 2020$ by author(s) and Scientific Research Publishing Inc. This work is licensed under the Creative Commons Attribution International License (CC BY 4.0).

http://creativecommons.org/licenses/by/4.0/

\begin{abstract}
Background: Postmenopausal bleeding (PMB) is caused mainly by benign disorders; however it is sometimes caused by endometrial cancer. Aim: We here attempted to determine what conditions account for PMB in an outpatient clinic of a University hospital in London. Methodology: Study subjects consisted of 179 patients with PMB who were referred to us from July to December 2019. Sociodemographic data including patient's age, risk factors, diagnosis and management were reviewed. Underlying conditions where determined. Results: Of 179 subjects, the following findings were made: 1) Age $59.63 \pm 8.3$ (mean and standard deviation). 2) Parity; multiparity, 57.0\% (mean \pm 1.67). 3) First episode of PMB, 77.1\%. 4) The most frequently observed risk factor; obesity $34.6 \%$. 5) The following accounted for PMB (diagnosis in order of incidence rate); genital atrophy $37.4 \%$, submucosal fibroid $28.5 \%$, endometrial polyp $20.7 \%$, endometrial hyperplasia $6.7 \%$, and endometrial cancer $5.6 \%$. All patients were treated appropriately. We did not determine the prognosis of patients with endometrial cancer. Conclusion: Although the incidence of rate among women with PMB has already been reported, its reconfirmation in a single facility is important for making policies in the treatment of PMB.
\end{abstract}

\section{Keywords}

Endometrial Cancer, Postmenopausal Bleeding

\section{Introduction}

Vaginal bleeding after the menopause is a concerning health issue in postmeno- 
pausal women [1]. Postmenopausal bleeding (PMB) is defined as any bleeding from the female genital tract after after the menopause [2] [3] [4]. The source of bleeding is commonly the uterus but may also be from the cervix, vagina, vulva or related to pathologies of the ovaries and tubes.

Postmenopausal bleeding accounts for about 5\% of Gynaecological referrals [4]. In the majority, the cause is benign but may also indicate a sinister pathology including endometrial cancer. Endometrial cancer is diagnosed in $3 \%-10 \%$ of women presenting with PMB [2] [3] [4]. Investigating women with postmenopausal bleeding is good clinical practice because endometrial cancer is the most common gynaecological malignancy in developed countries; long term survival depends on early diagnosis and treatment [5].

Causes of PMB include genital tract atrophy, endometrial hyperplasia, endometrial polyps, endometrial cancer, cervical pathologies including cervical cancer, hormone replacement therapy, ovarian and tubal pathologies [6]-[14]. By far the commonest cause is genital tract atrophy, although endometrial cancer is the most serious differential diagnosis and should be excluded [7] [8]. At-risk women for endometrial cancer are nulliparous women, advanced age, obesity, diabetes and hypertension, systemic exogenous estrogen therapy, tamoxifen, Lynch syndrome and late menopause [2] [7].

We here attempted to determine what conditions account for PMB in an outpatient clinic of a University hospital in London.

\section{Subjects and Methods}

We retrieved retrospective electronic data of consecutive patients managed for PMB from July 2019 to December 2019. Anonymised sociodemographic data including patient's age, risk factors, diagnosis and management were reviewed. Data were entered into an excel spreadsheet and statistical analyses performed using the SPSS software package, version 21 (IBM-SPSS Chicago, IL, USA).

Approval was obtained from the research and innovation directorate of the University Hospital.

\section{Results}

Table 1 shows the sociodemographic distribution of the study population. The mean age was $59.63 \pm 8.3$ years. A little over half of the study subjects where Caucasians $52.5 \%$ (94). More than half were multiparous $57.0 \%$ (102) with a mean parity of $1.81 \pm 1.67$ (mean and standard deviation).

Clinical presentation and risk factors are represented in Table 2. Majority of the patients $77.1 \%$ (138) were referred for the first episode of PMB. The most common risk factor was obesity $34.6 \%$ (62).

Table 3 shows the causes of PMB. The diagnosis in order of incidence rate); genital atrophy $37.4 \%$, submucosal fibroid $28.5 \%$, endometrial polyp $20.7 \%$, endometrial hyperplasia $6.7 \%$, and endometrial cancer $5.6 \%$. There was significant association between postmenopausal bleeding with genital atrophy and endo- 
Table 1. Sociodemographic characteristics.

\begin{tabular}{|c|c|c|}
\hline Parameter & & $\begin{array}{c}\text { Frequency (\%) } \\
\quad N=179\end{array}$ \\
\hline \multirow[t]{5}{*}{ Age (years) } & $<50$ & $8(4.5)$ \\
\hline & $50-59$ & $98(54.7)$ \\
\hline & $60-69$ & $45(25.1)$ \\
\hline & $70-79$ & $23(12.8)$ \\
\hline & $\geq 80$ & $5(2.8)$ \\
\hline \multirow[t]{3}{*}{ Race } & Asian & $28(15.6)$ \\
\hline & Black & $57(31.8)$ \\
\hline & Caucasian & $94(52.5)$ \\
\hline \multirow[t]{3}{*}{ Parity } & Nulliparous & $57(31.8)$ \\
\hline & Primipara & $20(11.2)$ \\
\hline & Multipara & $102(57)$ \\
\hline
\end{tabular}

Table 2. Clinical presentation and risk factors of postmenopausal bleeding.

\begin{tabular}{ccc}
\hline Variable & & Frequency (\%) \\
\hline Presentation & Primary & $138(77.1)$ \\
Risk factors for PMB & Secondary & $41(22.9)$ \\
& Smoking & $2(1.1)$ \\
& Family history of endometrial cancer & $5(2.8)$ \\
Hypertension & $36(20.1)$ \\
Obesity & $62(34.6)$ \\
Diabetes & $26(14.5)$ \\
& Adenomyosis/endometriosis & $7(3.9)$ \\
Hormone replacement therapy & $20(11.2)$ \\
\hline
\end{tabular}

Table 3. Aetiology, and treatment of post-menopausal bleeding.

\begin{tabular}{cccc}
\hline & Variable & Frequency (\%) & p-value \\
\hline Pathology & Atrophic endometritis and vaginitis & $67(37.4)$ & 0.004 \\
Endometrial cancer & $10(5.6)$ & 1.000 \\
Endometrial hyperplasia & $12(6.7)$ & 0.007 \\
Polyp & $37(20.7)$ & 0.208 \\
Fibroid & $51(28.5)$ & 0.544 \\
Treatment & Cancer of the cervix & $2(1.1)$ & 0.204 \\
& Oestrogen cream & $32(17.9)$ & \\
& Mirena/Norethisterone & $6(3.4)$ & \\
TAH/BSO & $11(6.1)$ & \\
Polypectomy & $37(20.7)$ & \\
& TCRF (Transcervical resection of fibroid) & $11(6.2)$ & \\
None & $70(39.1)$ & \\
\hline
\end{tabular}


metrial hyperplasia $(\mathrm{p}<0.05)$

In terms of treatment, modalities of treatment include polypectomy, estrogen cream, progestin, but $6.1 \%$ of the subjects underwent total abdominal hysterectomy and bilateral oophorectomy (TAH/BSO). The rest were managed expectantly.

\section{Discussion}

Postmenopausal bleeding (PMB) could present as an ominous sign of an endometrial pathology especially cancer, hence the aphorism "beware of the weeping womb" [10]. It accounts for about $5 \%$ of gynaecological referrals and estimated to affect $7 \%-15 \%$ of postmenopausal women [10] [11].

In developed countries, the lifetime risk of developing endometrial cancer is $1.1 \%$ while the lifetime risk of dying from the disease is $0.4 \%$ [14]. In this study, $5.6 \%$ of the subjects had endometrial cancer. This is similar to incidence rate reported from similar studies [3]-[12]. Postmenopausal status is a major risk factor for endometrial cancer [10] [13]. With increasing life expectancy, women now live about a third of their lifespan in menopause [15]. Although PMB is not synonymous with endometrial cancer, over $90 \%$ of women diagnosed with endometrial cancer had vaginal bleeding [9] [12]. Similarly, we found the mean age of the subjects to be 59 years with $2.8 \%$ of them in their 80 s. Obesity is an independent risk factor for endometrial cancer and hyperplasia, medical conditions including diabetes and hypertension are prevalent in obese women [4] [13]. This study showed that a little over a third $34.6 \%$ of our patients were obese and $20.1 \%$ and $14.5 \%$ respectively had hypertension and diabetes.

Management of postmenopausal bleeding is individualized depending on the diagnosis and individual patient characteristics and preferences. In our series, referred patients were seen through the 2-week wait pathway. These included patients with endometrial thickness of more than $5 \mathrm{~mm}$, recurrent $\mathrm{PMB}$ or co-existing endometrial pathologies. All the patients had pelvic ultrasound scan. The sensitivity and specificity of TVUS in detecting endometrial pathologies have been investigated in different studies and reported to range between 97\% $98 \%$ and $81 \%$ - 95\% respectively [12]. Diagnostic hysteroscopy and biopsy either in the outpatient setting or under general anaesthetic were done for all the patients meeting the inclusion criteria. Studies have shown hysteroscopy to be reliable and safe in the evaluation of endometrial lesion, it also affords the operator the chance to take directed biopsies and can be employed for "see and treat" [1].

The most common cause of postmenopausal bleeding in this study was atrophic endometritis and vaginitis in $37.4 \%$ of cases while uterine fibroid, endometrial polyp, endometrial hyperplasia and endometrial cancer were reported in $28.5 \%, 20.7 \%, 6.7 \%$ and $5.6 \%$ respectively. This is similar to findings reported in studies [1] [4] [7] [10]. Majority of the patients where managed conservatively. Patients with endometrial cancer were referred to oncology, oestrogen creams were used in the treatment of atrophic vaginitis and polypectomy for polyps. 
About $39.1 \%$ of the patients were either managed expectantly or declined any medical treatment.

In conclusion, endometrial cancer continues to be diagnosed in women with PMB. This reconfirmation in a single facility is important for making policies in the treatment of PMB. One major limitation of this study is that prognosis for patients managed for endometrial cancer was not explored.

\section{Conflicts of Interest}

We declare no conflict of interest.

\section{References}

[1] Bar-On, S., Ben-David, A., Rattan, G. and Grisaru, D. (2017) Is Outpatient Hysteroscopy Accurate for the Diagnosis of Endometrial Pathology among Perimenopausal and Postmenopausal Women? Menopause, 25, 160-164.

https://doi.org/10.1097/GME.0000000000000961

[2] Kitson, S.J. and Crosbie, E.J. (2019) Endometrial Cancer and Obesity. The Obstetrician \& Gynaecologist, 21, 1-6. https://doi.org/10.1111/tog.12601

[3] Moodley, M. and Roberts, C. (2004) Clinical Pathway for the Evaluation of Postmenopausal Bleeding with an Emphasis on Endometrial Cancer Detection. Journal of Obstetrics and Gynaecology, 24, 736-741. https://doi.org/10.1080/014436104100009394

[4] So, P.L., Sin, W.K., Lee, H.C. and Yeung, K.C. (2012) Evaluation of Recurrent Postmenopausal Bleeding. HKJGOM, 12, 69-79.

[5] Van Hanegem, N., Breijer, M.C., Khan, K.S., Clark, T.J., Burger, M.P., Mol, B.W. and Timmermans, A. (2011) Diagnostic Evaluation of the Endometrium in Postmenopausal Bleeding: An Evidence-Based Approach. Maturitas, 68, 155-164. https://doi.org/10.1016/j.maturitas.2010.11.010

[6] Denny, L. and Anorlu, R. (2012) Cervical Cancer in Africa. Cancer Epidemiology, Biomarkers \& Prevention, 21, 1434-1438. https://doi.org/10.1158/1055-9965.EPI-12-0334

[7] Brand, A.H. (2007) The Woman with Postmenopausal Bleeding. Australian Family Physician, 36, 116-120.

[8] van Hanegem, N., Breijer, M.C., Slockers, S.A., Zafarmand, M.H., Geomini, P.M.A.J., Catshoek, R., et al. (2017) Diagnostic Workup for Postmenopausal Bleeding: A Randomised Controlled Trial. BJOG, 124, 231-240.

[9] De Franciscis, P., Riemma, G., Schiattarella, A., Cobellis, L., Guadagno, M., Vitale, S.G., et al. (2019) Concordance between the Hysteroscopic Diagnosis of Endometrial Hyperplasia and Histopathological Examination. Diagnostics, 9, 142. https://doi.org/10.3390/diagnostics9040142

[10] Ghoubara, A., Sundar, S. and Ewies, A.A.A. (2018) Endometrial Pathology in Recurrent Postmenopausal Bleeding: Observational Study of 385 Women. Climacteric, 21, 391-396. https://doi.org/10.1080/13697137.2018.1461825

[11] Smith, P.P., O’Connor, S., Gupta, J. and Clark, T.J. (2014) Recurrent Postmenopausal Bleeding: A Prospective Cohort Study. The Journal of Minimally Invasive Gynecology, 21, 799-803. https://doi.org/10.1016/j.jmig.2014.03.007

[12] Goldstein, R.B., Bree, R.L., Benson, C.B., Benacerraf, B.R., Bloss, J.D., Carlos, R., et al. (2001) Evaluation of the Woman with Postmenopausal Bleeding: Society of Ra- 
diologists in Ultrasound-Sponsored Consensus Conference Statement. Journal of Ultrasound in Medicine, 20, 1025-1036.

https://doi.org/10.7863/jum.2001.20.10.1025

[13] Sean, K. (2018) Endometrial Cancer. In: Edmonds, D.K., Lees, C. and Bourne, T., Eds., Dewhurst's Textbook of Obstetrics and Gynaecology. 9th Edition. Willey Blackwell, Oxford, 876-883. https://doi.org/10.1002/9781119211457.ch62

[14] ACOG Committee Opinion No. 426 (2009) The Role of Transvaginal Ultrasonography in the Evaluation of Postmenopausal Bleeding. International Journal of $G y$ necology \& Obstetrics, 56, 115-127.

[15] Fagioli, R., Vitagliano, A., Carugno, J., Castellano, G., De Angelis, M.C. and Di Spiezio, A. (2020) Hysteroscopy in Postmenopause: From Diagnosis to the Management of Intrauterine Pathologies. Climacteric, 23, 360-368.

https://doi.org/10.1080/13697137.2020.1754387 